\section{Root Traits Play a Role in Integrated Management of Fusarium Root Rot in Snap Beans}

\author{
S. Snapp ${ }^{1}$, W. Kirk², B. Román-Avilés ${ }^{3}$, and J. Kelly ${ }^{3}$ \\ Michigan State University, East Lansing, MI 48824
}

\begin{abstract}
Additional index words. Phaseolus vulgaris, disease resistance, genetics, Fusarium solani, root architecture
\end{abstract}

\begin{abstract}
Fusarium root rot is a major limiting factor in snap bean (Phaseolus vulgaris L.) production. The level of genetic resistance in commercial bean cultivars is minimal and disease is frequently exacerbated by environmental factors. We investigated the contribution of vigorous, adventitious roots to enhancing root rot tolerance in snap bean. Seedling root system architecture was evaluated in 17 recombinant inbred lines (RILs) from a cross of a resistant snap bean line (FR266) and a susceptible dry bean cultivar (Montcalm). The RILs varied in tolerance to F usarium root rot. Although overall length and branching density (as measured by fractal dimension and meristem numbers) of root systems were not related to root rot resistance, the lateral root number at the root : shoot interface was positively correlated with genotype tolerance $\left(R^{2}=0.6^{*}\right)$. Root diameter was also positively correlated with tolerance; this is consistent with the hypothesis that larger adventitious and basal roots are beneficial under disease stress. A field-based study of commercial snap bean cultivars compared raised and flat-bed systems of production, in a soil inoculated with $F$ usarium solani $\mathrm{f}$. sp. phaseoli. Substantially greater yields $(40 \%$ to $90 \%$ ) were observed in raised beds. Root vigor was relatively high (root length density $>0.2 \mathrm{~cm} \cdot \mathrm{cm}^{-3}$ ) and root rot scores were lower with raised than with flat-beds, in 2001, but not in 2000. Overall, this is suggestive that integrated crop management practices can improve lateral root vigor and reduce root rot severity.
\end{abstract}

Root rot is a worldwide problem in snap bean (Phaseolus vulgaris L.) production(Dickson and Boettger, 1977; Schneider et al., 2001). Environmental stress, including intermittent drought, soil saturation, soil compaction, and cool soil temperatures predispose bean plants to severe root rot (Burke and Miller, 1983; Saettler and Anderson, 1982). In most regions the primary causal agent of root rot in bean is Fusarium solani f. sp. phaseoli (Silbernagel and Mills, 1990), although Pythium species and Rhizoctonia solani Kuhn are also implicated in the disease complex (Dickson and Boettger, 1977). Control of Fusarium root rot is an intractable problem, as appropriate fungicide materials are expensive, not always effective and increasingly highly regulated. Further, genetic resistance to root rots is limited in the narrow genetic base of cultivars that meet the strict, market-driven quality traits for snap bean and closely related genotypes such as dark red kidney dry bean (Gepts, 1998).

A hypocotyl assay has been widely used to study the root rot disease complex (Furuya, et al., 1999; Hassan, et al., 1971). Inadvertent selection for ineffective root systems may have occurred in screening nurseries with highly amended soils and disease-controlled environments. For example, modern, improved cultivars of lettuce (Lactuca sativa) and other vegetables have relatively shallow root systems

Received for publication 5 Feb. 2002. Accepted for publication 25 June 2002.

${ }^{1}$ Dept. of Horticulture.

${ }^{2}$ Dept. of Plant Pathology.

${ }^{3}$ Dept. of Crop and Soil Sciences. and low root: shoot ratios, compared with older land races and their wild progenitors (Jackson and Koch, 1997; O'Toole and Bland, 1987). Potentially these root systems are vulnerable and ineffective without high rates of nutrient inputs and application of fungicide or fumigation. Cultural practices that reduce root restriction also tend to reduce the severity of root rot infection (Burke and Miller, 1983; Silbernagel and Mills, 1990). Understanding possible relationships between Fusarium root rot severity and root system architecture and morphological characteristics could lead to more effective management of the disease. Cultural practices and genetic screening assays could then be tailored to enhance the appropriate root traits, and thus root rot resistance.

Quantitative evaluation of root traits is challenging given the methodological difficulties of studying the "hidden half" and high root plasticity (Lynch and Beebe, 1995; Snapp et al., 1995). The importance of vigorous lateral and adventitious rooting has been suggested but quantitative data are lacking (Abawi et al. 1985; Dickson and Boettger, 1977). Inbred lines from a cross of a Fusarium-resistant (FR266) snap bean genotype and a standard, susceptible bean cultivar (Montcalm) provide an opportunity to examine a range of rooting traits. The recombinant inbred lines (RILs, $\mathrm{F}_{4: 8}$ ) from the cross provide a wide range of material with variable resistance to Fusarium root rot (Schneider et al., 2001). Root system architecture was not characterized for the RILs, but FR266 was described by Silbernagel (1987) as having an unusually vigorous root system with many adventitious roots. Thus RILs with FR266 as a parent might reasonably be expected to have variable root traits, as 'Montcalm' is known to root poorly. Variation in adventitious rooting can also be studied using cultural practices (Bonser et al., 1996). Modification of the environment through use of planting beds enhances adventitious rooting in a number of vegetable crops (Leskovar and Stoffella, 1995). Thus cultural, as well as genetic manipulation, can be used to investigate root traits and plant resistance to root rot.

This research focused on root system characteristics that could affect tolerance to root-rots, including production of lateral roots that branch from the main root system near the root/shoot interface. These are frequently referred to as adventitious roots, although, by definition, such roots arise from hypocotyl tissue. Roots that arise from the shoot-root transition zone have been termed basal roots (Leskovar and Stoffella, 1995).

The objectives of this study were to test if a vigorous root system with multiple and substantial adventitious rooting would improve root rot tolerance in snap bean. Two lines of investigation were pursued. First, the association of root traits with root rot resistance was tested through a genetic comparison of 20 bean lines. The genotypes were evaluated in a glass chamber assay and included inbred lines from the cross of a resistant and a susceptible cultivar. Second, the effect of a raised bed vs. a standard flat production system was evaluated as a means to promote adventitious roots and reduce root rot in beans.

\section{Materials and Methods}

\section{Genetic study}

Genotypes studied. Twenty genotypes were selected for the study, including two susceptible cultivars, 'Montcalm' and 'Red Hawk', one resistant parent 'FR266', and 17 recombinant inbred lines $\left(\mathrm{F}_{4: 8}\right)$ from the Montcalm x FR266 cross (Schneider et al., 2001). The lines were previously evaluated for root rot resistance level in 2 years of greenhouse and field-testing. They varied markedly in root rot resistance, with scores from $\approx 2$ to 6 (a scale was used to evaluate root rot severity from 1 to 7 , where $1=$ no disease or very slight root discoloration, 2 to $6=$ intermediate and increasing severity of discoloration and lesion development, and $7=$ senescence and root system completely covered with lesions; Schneider and Kelly, 2000). The inbred lines included in this study were selected randomly from the 100 plus RILs that were developed from the cross. Four replications of each line were included in this study.

Plant growth and management. Seedling bean root growth was evaluated using root observation chambers (Fig. 1). This technique was modified from a growth pouch method (Bonser et al., 1996). A range of growth media were initially screened for ability to provide a uniform background in imaging and a relatively homogeneous growth medium with aeration, texture, and resistance characteristics similar to those of a sandy loam soil, thus 


\section{Crop Production}

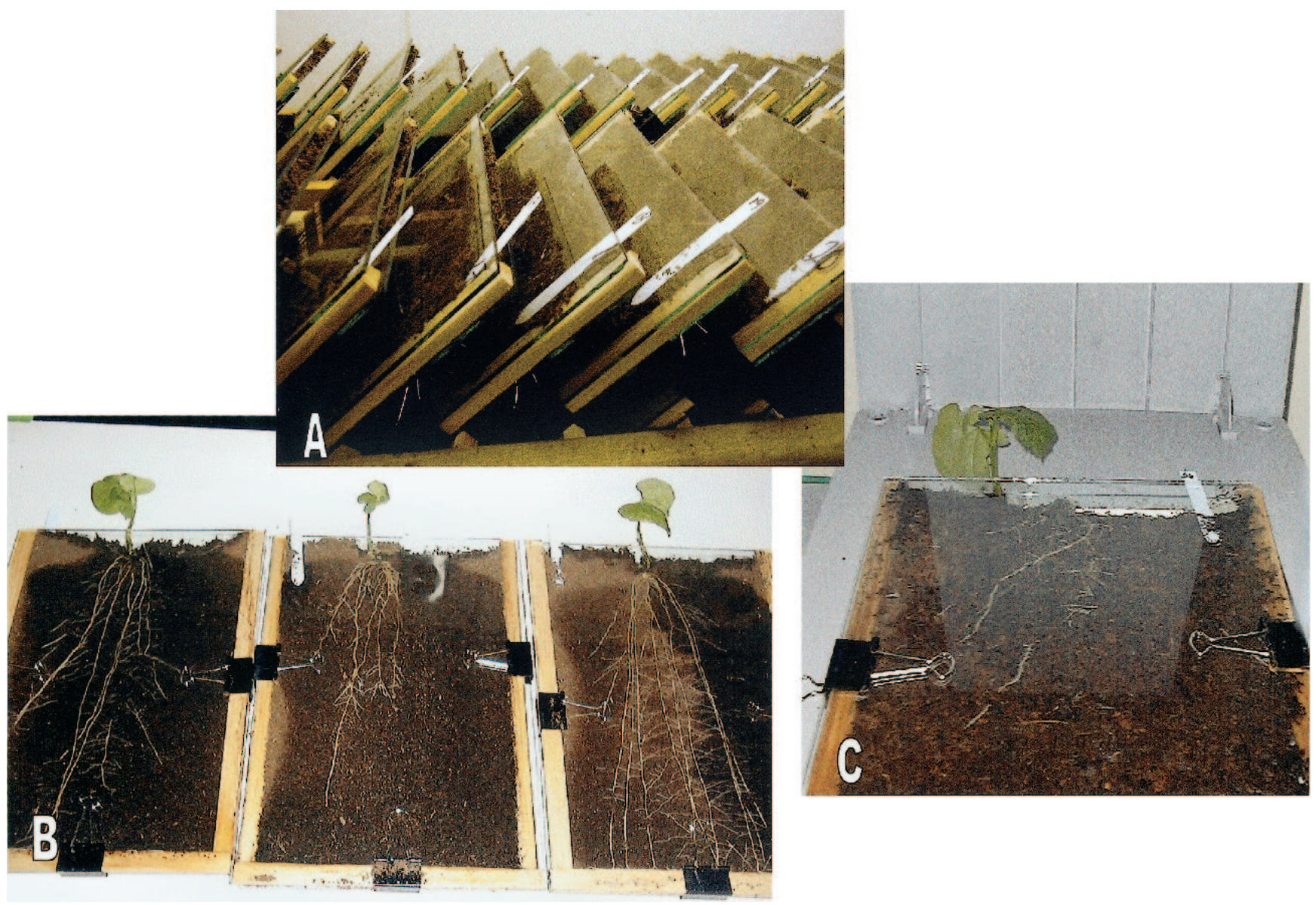

Fig. 1. (A) Glass root system chambers installed at a $45^{\circ}$ slant in the growth chamber. (B) Root systems of bean seedlings grown in the chambers at the first measurement time, $15 \mathrm{~d}$ after emergence. C) A glass chamber inverted and placed on the scanner to record the root system image.

supporting normal development of root system architecture (Snapp et al., 2001). The growth medium chosen for the glass chamber assay was coconut fiber, a relatively inert material with uniform distribution of aeration and water holding capacity. Seeds were germinated on germination paper and uniform seedlings were placed in the top centimeter of the medium. Growth under uniform moisture conditions was achieved by application of dilute nutrient solution every other day. The growth chamber was maintained at $28^{\circ} \mathrm{C}$ day $/ 25^{\circ} \mathrm{C}$ night. All plants were inoculated $5 \mathrm{~d}$ after emergence (dae) with Fusarium solani f. sp. phaseoli, using $10 \mathrm{~mL}$ of $2 \times 10^{5}$ spores $/ \mathrm{mL}$. Mixed suspensions of microconidia and macroconidia were prepared from Fusarium solani f. sp. phaseoli cultures of a single isolate (FSPMI-HawksB) grown on potato dextrose agar plates for $21 \mathrm{~d}$ in $12 \mathrm{~h} \mathrm{light/}$ $12 \mathrm{~h}$ dark at $15^{\circ} \mathrm{C}$. Preliminary studies were carried out to determine appropriate inoculation procedures to obtain uniform coverage and a moderate infection level at $10 \mathrm{~d}$.

Root system observations. On two occasions, at $10 \mathrm{~d}$ after inoculation (15 dae), and 9 $\mathrm{d}$ subsequently, the root system observable on the lower side of the chamber was scored for root rot symptoms (score $=1$ to 7 , as described above). The pathogens responsible for the lesions were further distinguished by isolation on selective media for randomly chosen root tissue segments, where Fusarium solani was the pathogen isolated in all cases. After $24 \mathrm{~d}$, four replications of each line were harvested over $4 \mathrm{~d}$, one replication per day. Root systems were washed out of the growth medium, arranged on a glass sheet using tweezers to fully separate roots, and the image was scanned and analyzed.

A high resolution scanner was used to record root system architecture and to save the image for scoring of root rot lesion severity and analysis of root system traits. Scanner images were processed to produce a uniform background and for calibration purposes, then analyzed using the software WinRhizo (2001). This allowed measurement of whole root system length, average root diameter, fractal dimension (an indicator of branching density and space-filling properties of the root system), and number of meristems (Berntson et al., 1995). Manual counting was conducted to determine the number of root system laterals in the top $1-\mathrm{cm}$ zone of the root system (Johnson et al., 2000). Scoring of images for severity of root rot infection was conducted using the previously described 1 to 7 scale, where $1=$ no symptoms and $7=$ severely infected.

\section{Cultural management study}

Field site. The field plot site was located on the Southwest Michigan Research and Ex- tension Center, near Benton Harbor, Mich. The soil type was an Oakville fine sand, a mixed, mesic Typic Udipsamments, typical of snap bean production sites in the region. The field was inoculated with mixed suspensions of microconidia and macroconidia from Fusarium solani f. sp. phaseoli cultures as described previously for the genetic study. A mycelialconidial suspension was stirred, strained and the concentration of conidia was adjusted to $\approx 1$ $\times 10^{3}$ sporangia $/ \mathrm{mL}$ using a haemacytometer. All plots were inoculated with $150 \mathrm{~mL} \cdot \mathrm{m}^{-2}$ trial area on 29 June, 2000 and 26 June, 2001.

Commerical cultivar root rot severity and yield were compared for two soil management systems: 1) standard flat production; and 2) raised beds. Raised planting beds were constructed using a commercial vegetable bed shaper and were $0.85 \mathrm{~m}$ wide $\times 0.15 \mathrm{~m}$ high. Three commercially grown snap bean cultivars ('Topcrop', 'Bronco', and 'Hercules') were compared in 2000; six cultivars ('Hystyle', 'Bronco', 'Minuette', 'BBL 156', 'Labrador', and 'Red Hawk') were compared in 2001. The cultivars were chosen in consultation with industry representatives to represent diverse market types. Plot size was 4 rows $3 \mathrm{~m}$ long; between row spacing was $0.6 \mathrm{~m}$ for standard flat production and $0.8 \mathrm{~m}$ for the raised bed system. The experimental design was a splitplot with four replications. The main plot was bed system and the subplot was cultivar. 
Cultural management practices followed Michigan State Univ. recommendations, including pre-plant fertilizer at $60 \mathrm{lb} /$ acre $\mathrm{N}$ as ammonium nitrate (soil $\mathrm{P}$ and $\mathrm{K}$ levels were sufficient). The preplant herbicide used was Dual, and Sevin insecticide was applied during the growing season. Tensiometers were used to evaluate soil moisture and adjust irrigation scheduling to $20 \%$ higher than recommended, in order to enhance Fusarium root rot incidence (Saettler and Anderson, 1982). A total of 105 $\mathrm{mm}$ irrigation water was applied in 2000 and $130 \mathrm{~mm}$ in 2001.

Plant evaluation. Beans were planted on 28 June 2000 and 15 June 2001 and plant stand counts were conducted 14 July 2000 and 28 June 2001. Stands established were not significantly influenced by treatments in either year, and on average reached the target population density of 13 plants/m of row.

Scoring of root rot symptoms was carried out on 20 July and 21 Aug. 2000 and 26 July and 20 Aug. 2001. Four plants were randomly selected from the external two rows of each plot, a 200-mm-radius $\times 200$-mm-deep area was excavated using a shovel to obtain a relatively intact root system, and the root system washed. Each plant was scored separately for symptoms using a scale of 0 to $4(0=$ healthy plant, 1 = few lesions on hypocotyl, $2=$ increased discoloration/larger lesions on central root system, $3=$ entire hypocotyl severely discolored, and $4=$ dead/dying plant). The pathogens responsible for the lesions were distinguished by isolation on selective media for randomly chosen root tissue segments; Fusarium solani was the primary pathogen isolated.

Root traits were evaluated in 2000 and in 2001. In 2000, adventitious root scoring was determined on the same root systems that were excavated to determine root rot severity. The scoring system used was a visual scale of 1 to 4 , where 1 = weak adventitious roots with less than 5 small lateral roots originating in the top $5 \mathrm{~cm}$ of the root/shoot interface, $2=$ intermediate adventitious vigor with four to seven lateral roots in the top $5-\mathrm{cm}$ region, $3=$ moderately vigorous adventitious roots with about seven to ten lateral roots, and $4=$ highly vigorous adventitious roots with greater than nine substantial lateral roots in the top $5-\mathrm{cm}$ of the root/shoot interface. Two individuals did all of the adventitious scoring to minimize variability. In 2001 root length density was measured, instead of scoring adventitious roots. Six sub-sample cores $50 \mathrm{~mm}$ in diameter $\times$ $200 \mathrm{~mm}$ deep were taken per plot, randomly within the row. Soil samples were wet-sieved to pass a $2 \mathrm{~mm}$ pore sieve. Recovered roots were transferred to glass plates, the image was scanned and Winrhizo analysis of root length was conducted as described above.

Beans were harvested on 28 Aug. 2000 and 21 August 2001. Two, 1.5-m sections of interior rows were harvested by hand picking all beans and total fresh biomass was determined for all pods longer than $50 \mathrm{~mm}$.

Statistical analysis. Data were analyzed by analysis of variance (ANOVA) using a splitplot model with bed system as the main plot and cultivar as the subplot (Statistica, 1999). Linear regression of root traits vs. Fusarium root rot score was conducted for data from root systems of bean lines grown in glass root observation chambers. All data were checked for normality by plotting residuals vs. predicted values.

\section{Results and Discussion}

Genetic study. Root rot scores of RILs in the chamber system were highly correlated $\left(R^{2}\right.$ $=0.9^{* *}$, data not shown) with previous root rot severity ratings established in field and greenhouse studies, confirming variation in tolerance to root rot in these lines (Schneider et al., 2001). Overall length of the root system, fractal dimension (an indicator of branching density and space-filling properties of the root system) and number of meristems were not related to genotype root rot tolerance (data not shown). In contrast, average root diameter and root lateral branch number in the top $1-\mathrm{cm}$ zone of the root system were associated with severity of root rot tolerance score and will be discussed here (Fig. $2 \mathrm{~A}$ and B).
Root studies have to contend with extreme plasticity in growth responses to environment and thus high variability (O'Toole and Bland, 1987). Although root system diameter at the first sampling was not significantly correlated with the root rot tolerance of inbred lines, it was negatively correlated with root rot severity $\left(R^{2}\right.$ $=0.4^{*}$, Fig. $\left.2 \mathrm{~A}\right)$ at the second measurement. Thick roots may be associated with a root system that has a large number of substantial adventitious and basal roots. Ten $\mathrm{d}$ after inoculation with Fusarium solani f. sp. phaseoli, the number of lateral roots in the top centimeter was not related to root rot infection severity. However, after $18 \mathrm{~d}$ of growth (Figs. 2A and 2B), laterals increased in the top centimeter of root/shoot interface. The average number of laterals in the top centimeter varied from 3 to 11 and was positively correlated with genotype root rot tolerance $\left(R^{2}=0.6\right.$, Fig. 2B). Interestingly, the tolerant line FR266 had the highest number of lateral roots in the top centimeter and the susceptible Montcalm had the least number.

Root systems with many adventitious roots may escape some negative effects of disease
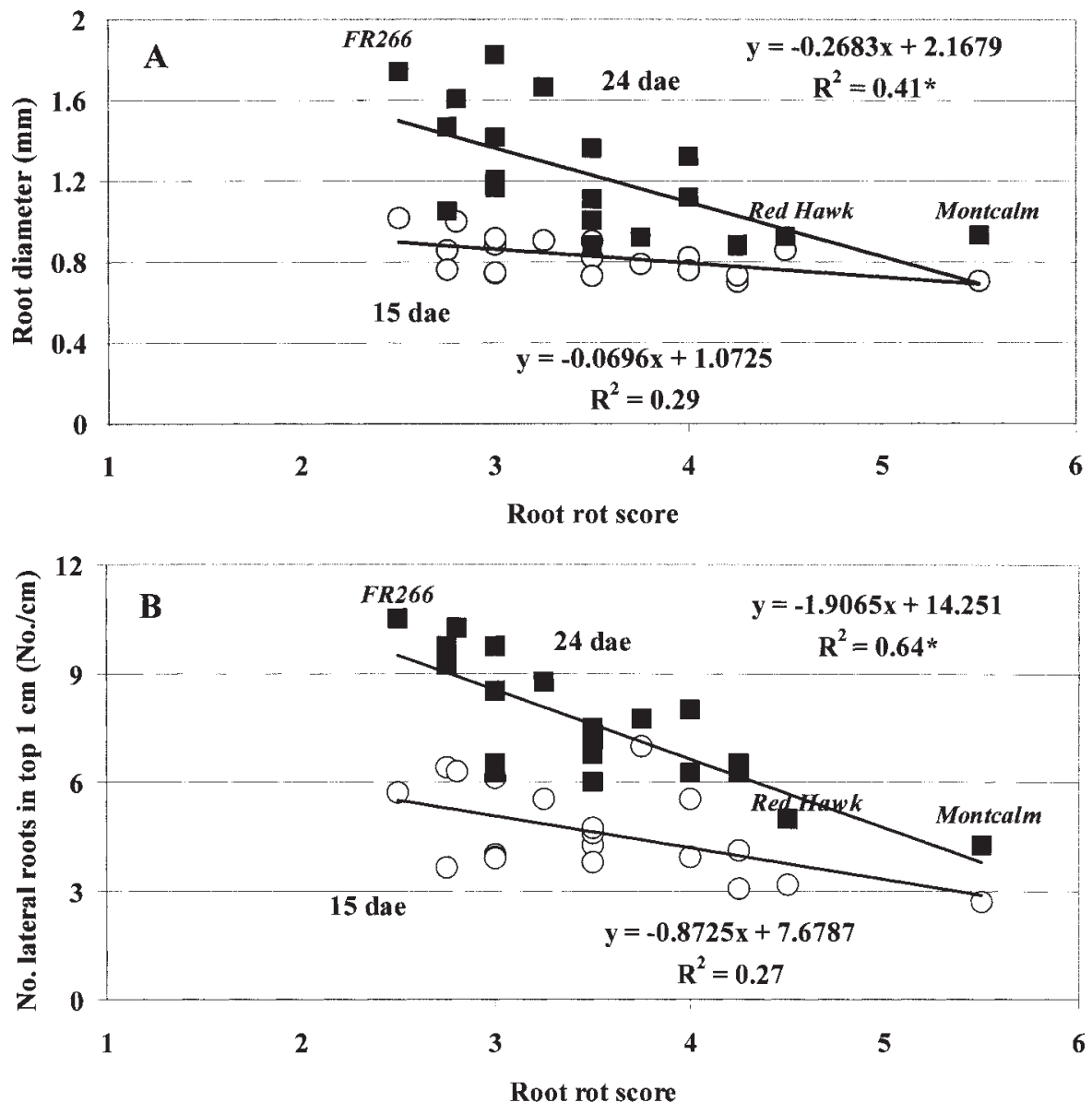

Fig. 2. (A) Average diameter (four replications) of seedling root systems regressed against average root rot resistance score $(1-7$, where $7=$ severe Fusarium root rot) of 20 bean genotypes (17 RILs plus three parent lines), all grown in glass root chambers. Circles represent measurements conducted $15 \mathrm{~d}$ after emergence (dae) and squares represent measurements conducted 24 dae. Regression lines are shown for the two measurement dates. (B) Average number of lateral roots (four replications) from the top 1-cm zone of the root system from four replications of seedling root systems regressed against average root rot resistance score (1-7, where $7=$ severe Fusarium root rot) of 20 bean genotypes (17 inbred lines plus three parent lines), all grown in glass root chambers. Circles represent measurements conducted $15 \mathrm{~d}$ after emergence (dae) and squares represent measurements conducted 24 dae. Regression lines are shown for the two measurement dates. 

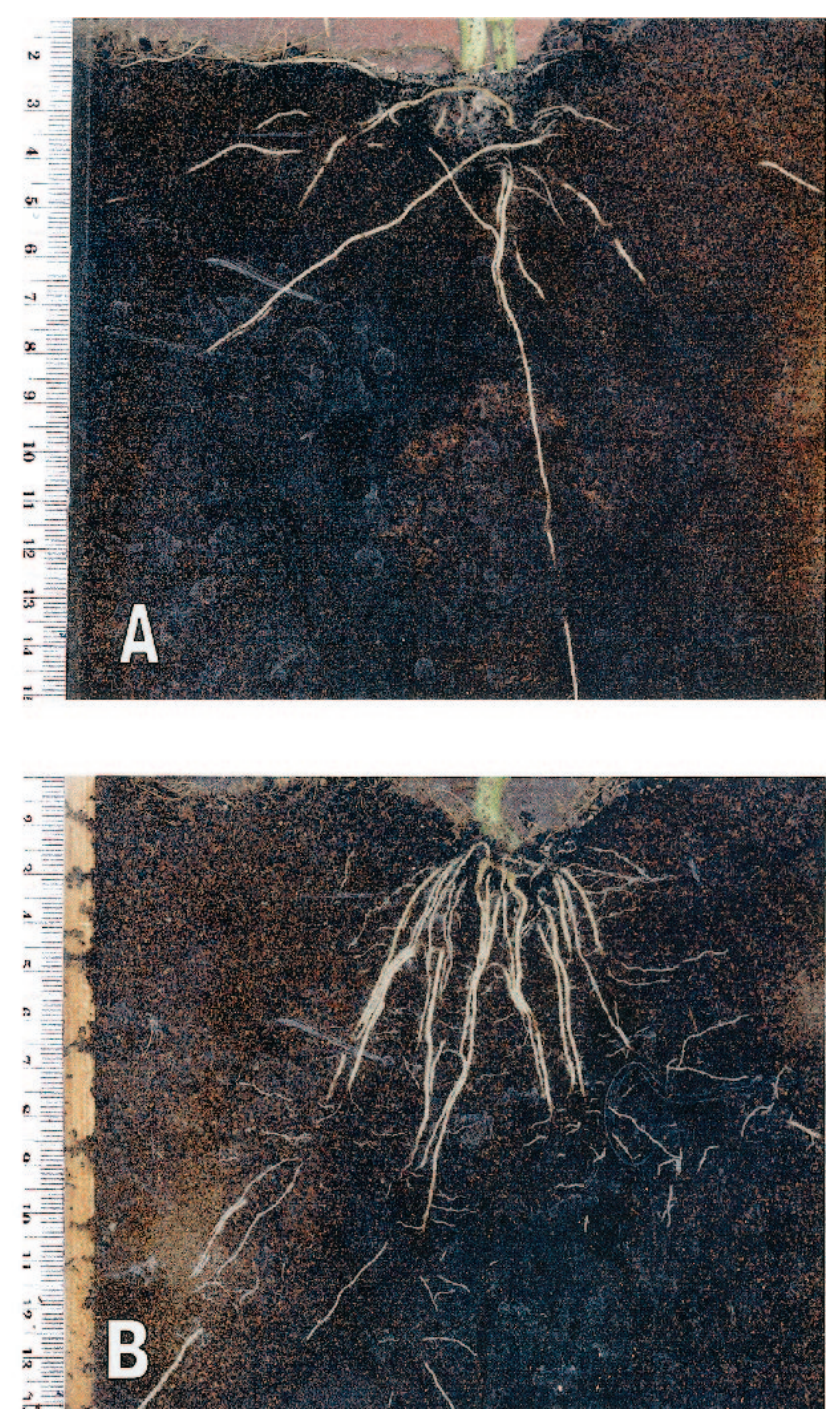

Fig. 3. Representative root systems of: (A) a susceptible parent 'Montcalm' dry bean and (B) a resistant parent 'FR266' snap bean.

by producing vigorous roots that compensate for the function of other lesion-infected roots. Compare, for example, the multiple lateral roots of a representative root system from the resistant parent line FR266 vs. the sparse lateral roots in the susceptible parent cultivar Montcalm (Fig. 3). A similar mode of resistance was observed in a tomato (Lycoperscion esculentum Mill.) cultivar CX8303, in which root growth outpaced senescence in response to Phytophthora root rot infection (Snapp and Shennan, 1994). Descriptive information about adventitious roots replacing function of infected main tap roots has been published previously (Abawi et al., 1985), although we are not aware of any previous quantitative data on this phenomenon. Agenetic study of the root architecture of inbred lines from lettuce and a wild lettuce progenitor (Johnson et al., 2000) also found lateral roots originating in the top zone of the root system to be one of the few traits that were predictive of stress tolerance-although drought stress tolerance was studied rather than root rot tolerance.

Seed color and size were not associated with resistance in this evaluation (data not shown). Earlier studies showed that large colored seeds such as dark red kidney market classes tend to be susceptible to Fusarium root rot (Gepts, 1998). Resistant, white-seeded genotypes have been identified previously, although they are rare (Dickson and Boettger, 1977; Gepts, 1998).

Cultural management study. Root rot was more severe in the flat production sys- tem than in the raised bed in 2001; but not in 2000 (Table 1). Intermittent soil saturation or cooler temperatures could have enhanced root rot more in the former system than in the raised beds. In both years the beans were planted in mid-June to avoid cool soil temperature and focus instead on root growth and soil structure aspects of root rot tolerance. A sandy loam soil was selected for the field experiment, as representative of the majority of commercial production environments and to avoid prolonged soil saturation. Intermittent soil saturation is encountered on snap bean production soils in Michigan, whereas prolonged flood-stress is rare, as growers avoid heavy soil. Intermittent oxygen stress can induce root rot even in resistant bean genotypes (Burke and Miller, 1983).

Root system length was somewhat higher in the raised bed than in the conventional flat production system, but the differences were not significant (Table 1). A vigorous root system may be associated with tolerance to Fusarium root rot infection in bean roots with already well-developed lesions (Burke and Miller, 1983). Scores for adventitious roots in 2000 , however, did not indicate any relationship between tolerance to Fusarium root rot infection and bean yield (data not shown).

Yield of cultivars grown in Fusarium-infested soil was enhanced by $40 \%$ (2000) and $90 \%$ (2001) in the raised bed system than on the flat (Table 1). Green bean yield of cultivars varied from 0.3 to $0.9 \mathrm{~kg} \cdot \mathrm{m}^{-1}$ on a linear row basis, which was equivalent to 3430 to $9070 \mathrm{~kg} \cdot \mathrm{ha}^{-1}$. No one cultivar showed a consistently greater resistance to root rot or a greater benefit from production on raised beds. Raised bed systems reduce root rot resistance in other vegetables, and are recommended for bean production in New York (Abawi et al., 1985). Combined benefits are expected from cultural practices such as raised bed systems, which in our study was associated with a larger root system; the soil may have been better drained as well (soil saturation was not measured). The considerable investment required for equipment and tillage requirements associated with raised beds are barriers to wide-spread adoption by growers. The substantial yield increase observed in our study, observed across diverse cultivars

Table 1. Effect of soil management system on root rot severity, root length density and green bean yield at a Fusarium inoculated sandy site near Benton Harbor, Mich. (average of four replications).

\begin{tabular}{lcccc}
\hline & \multicolumn{2}{c}{ Root rot score $(0-4)^{\mathrm{z}}$} & & \\
\cline { 2 - 3 } System & $\begin{array}{c}\text { Score 1 } \\
\left(\mathrm{cm} \cdot \mathrm{cm}^{-3}\right)\end{array}$ & $\begin{array}{c}\text { Score 2 } \\
\left(\mathrm{kg} \cdot \mathrm{m}^{-1}\right)\end{array}$ & $\begin{array}{c}\text { Root length } \\
\text { density }\end{array}$ & $\begin{array}{c}\text { Yield }^{\mathrm{y}} \\
(\text { linear row })^{\mathrm{w}}\end{array}$ \\
\hline Flat production & $0.52(0.17)^{\mathrm{v}}$ & $\begin{array}{c}2000 \\
1.75(0.17)\end{array}$ & $\mathrm{nd}^{\mathrm{u}}$ & $0.43(0.09)$ \\
Raised bed & $0.56(0.23)$ & $\begin{array}{c}1.70(0.14) \\
\text { nd }\end{array}$ & $0.60(0.05)$ \\
& & 2001 & & \\
Flat production & $2.38(0.17)$ & $2.04(0.38)$ & $0.18(0.04)$ & $0.41(0.08)$ \\
Raised bed & $2.08(0.10)$ & $1.52(0.21)$ & $0.24(0.05)$ & $0.78(0.12)$ \\
\hline
\end{tabular}

${ }^{2}$ Root rot scores determined from mean of four plants per plot.

'Yield measurements were conducted twice for each plot.

${ }^{x}$ Score 1 taken $15 \mathrm{~d}$ after emergence, score 2 taken $9 \mathrm{~d}$ later.

wYield is presented on a linear row basis to facilitate comparison of systems with different intra-row spacing.

'Standard error.

"nd $=$ not determined. 
representing different market types, warrants further study of the costs and benefits associated with the raised bed system. There may be more affordable tillage systems than raised beds - such as ridge production systems - that provide similar benefits in terms of promoting root vigor and soil aeration.

\section{Conclusions}

In these studies a large root system was associated with Fusarium root rot tolerance in bean. A substantial number of lateral roots in the top $1 \mathrm{~cm}$, at the root-shoot interface, were observed in genotypes with greater resistance to Fusarium root rot. Susceptible cultivars Montcalm and Red Hawk had the least number of lateral roots at the root : shoot interface, and tolerant FR266 had the highest number. Plant breeders may be able to improve root rot tolerance through focusing on root traits, although the result needs to be tested using a much larger number of genotypes than the 17 RILs and parents included here. Raised bed production was associated with reduced root rot in one year and improved yields in both years of field testing. Higher root length density was observed in raised beds versus flat production. This supports the use of integrated crop management practices to improve root system vigor. Further research should investigate how combined genotypes and cultural practices can promote adventitious and basal root development.

\section{Literature Cited}

Abawi, G.S., D.C. Crosier and A.C. Cobb. 1985. Root rot of snap beans in New York. New
York's Food and Life Sci. Bul. 110. New York State Agr. Expt. Sta., Geneva, N.Y.

Berntson, G.M., J.P. Lynch, and S.S. Snapp. 1995. Fractal geometry and plant root systems: Current perspectives and future applications, $\mathrm{p}$. 113-152. In: P. Baveye, J.Y. Parlange and B.A. Stewart (eds.). Fractals in Soil Science. Lewis Publ., New York.

Bonser, A.M., J.P. Lynch, and S.S. Snapp. 1996. Gravitrophic response to low $\mathrm{P}$ and root architectural traits in common bean. New Phytol. 132:281-288.

Burke, D.W. and D.E. Miller. 1983. Control of $F u$ sarium root rot with resistant beans and cultural management. Plant Dis. 67:1312-1317.

Dickson, M.H. and M.A. Boettger. 1977. Breeding for multiple root rot resistance in snap beans. J. Amer. Soc. Hort. Sci. 102:373-377.

Furuya, H., T. Takahashi, and T. Matsumoto. 1999. Suppression of Fusarium solani f. sp. Phaseoli on bean by aluminum in acid soils. Phytopathology 89:47-52.

Gepts, P.L. 1998. Origin and evolution of common bean: Past events and recent trends. HortScience 33:1124-1130.

Hassan, A.A., D.H. Wallace, and R.E. Wilkinson. 1971. Genetics and heritability of resistance to Fusarium solani f. sp. Phaseoli in beans. J. Amer. Soc. Hort. Sci. 96:623-627.

Jackson, L.E. and G.W. Koch 1997. The ecophysiology of crops and their wild relatives, p. 3-37. In: L.E. Jackson (ed.). Ecology in agriculture. Academic, San Diego.

Johnson, W.C., L.E. Jackson, O. Ochoa, R. van Wijk, J. Peleman, D.A. St. Clair, and R.W. Michelmore. 2000. Lettuce, a shallow-rooted crop, and Lactuca serriola, its wild progenitor, differ at QTL determining root architecture and deep soil water exploitation. Theor. Appl. Genet. 101:1066-1073.

Leskovar, D.I. and P.J. Stoffella. 1995. Vegetable seedling root systems: Morphology, development and importance. HortScience
30:1153-1159.

Lynch, J.P. and S.E. Beebe. 1995. Adaptation of beans (Phaseolus vulgaris L.) to low phosphorus availability. HortScience 30 : $1165-1171$

O'Toole, J.C. and W.L. Bland. 1987. Genotypic variation in crop plant root systems. Adv. Agron. 41:91-145.

Saettler, A.W. and A.L. Anderson. 1982. Bean diseases and their control, p. 172-179. In: L.S. Roberston and R.D. Frazier (eds.). Dry bean production - Principles and practices. Extension Bulletin E-1251, Michigan State Univ., Coop. Ext. Serv. Agr. Expt. Sta.

Schneider, K.A., K.F. Grafton, and J.D. Kelly. 2001. QTL analysis of resistance to Fusarium root rot in bean. Crop Sci. 41:535-542.

Schneider, K.A. and J.D. Kelly. 2000. A greenhouse screening protocol for Fusarium root rot in bean (Phaseolus vulgaris L.) HortScience 35: 1095-1098.

Silbernagel, M.J. 1987. Fusarium root rot-resistant snap bean breeding line FR266. HortScience 22:1337-1338.

Silbernagel, M.J. and L.J. Mills. 1990. Genetic and cultural control of Fusarium root rot in bush snap beans. Plant Dis. 74:61-67.

Snapp, S. S., R. Koide, and J.P. Lynch. 1995. Exploitation of localized P-patches by common bean roots. Plant and Soil 177:211-218.

Snapp, S.S., B. Roman, J.D. Kelly, and W. Kirk. 2001. Root traits involved in resistance to $F u$ sarium root rot in common bean. HortScience 36:511. (Abstr.)

Snapp, S. S. and C. Shennan. 1994. Salt stress effects on root growth and senescence in tomato and the consequences for severity of Phytophthora root rot infection. J. Amer. Soc. Hort. Sci. 119: 458-463.

Statistica, 1999. StatSoft statistical analytical software, Tulsa, Okla.

WinRhizo Software Manual. 2001. Regent Instruments, Quebec City, Canada. 